\title{
Closure of the Cystic Duct at Laparoscopic Cholecystectomy
}

\author{
Simon R Bramhall ${ }^{*}$, Moustafa M Mourad ${ }^{2}$ and Muhammad A Karim ${ }^{3}$ \\ ${ }^{1}$ County Hospital, Hereford, United Kingdom \\ ${ }^{2}$ Worcester Royal Infirmary, Worcester, United Kingdom \\ ${ }^{3}$ Walsall Manor Hospital, Walsall, United Kingdom \\ *Corresponding Author: Simon R Bramhall, Department of Surgery, The \\ County Hospital, Hereford, United Kingdom.
}

DOI: 10.31080/ASGIS.2020.03.0116

Keywords: Cystic Duct: Clip; Complications; Laparoscopic Cholecystectomy
Cholecystectomy is the commonest elective general surgical operation performed in the UK. The incidence of gallstones is increasing and the waiting time for cholecystectomy in the UK is also rising [1]. As a consequence of this and the changing demography of the patients the operation is becoming more challenging. The incidence of complications following laparoscopic cholecystectomy is higher in those with a high BMI, male sex, and those with a thick walled gallbladder such as associated with an empyema [2].

The majority of cholecystectomies are carried out laparoscopically and this allows the patients to recover more quickly and remain in hospital usually for less than 24 hours. The advantages to the patient, the hospital and the wider health economy are therefore obvious but there is a need to minimise complications as any complication will impact on the advantages that are accrued by successful laparoscopic surgery.

Probably the most common significant complication following laparoscopic cholecystectomy is a bile leak and this is reported to occur in up to $3 \%$ of routine laparoscopic cholecystectomies [3] but at rates of $4-7 \%$ in what are termed complicated laparoscopic cholecystectomies $[4,5]$. There are a number of potential reasons that increase the incidence of bile leakage post laparoscopic cholecystectomy and these include retained bile duct stones, wide cystic ducts, biliary strictures and technical problems. Cystic duct bile leakage is an unwanted and potentially life-threatening complication following laparoscopic cholecystectomy and every effort should be made to minimse the risk.

A number of methods have been described to seal or ligate the cystic duct; the commonest method used is the non-locking metal clude the pre-formatted loop (commonly termed Endoloop ${ }^{\oplus}$ ), suture ligation, intra-corporeal knot, locking clip, stapling devices or sealing with an energy device [6-9]. The choice of method is usually down to the surgeon and little evidence base exists to support one over another. There are perceived advantages and disadvantages to each approach but the choice usually comes down to expedience, clip (commonly termed Ligaclip ${ }^{\oplus}$ ) but other described methods in-
Published: January 29, 2020

(C) All rights are reserved by Simon R

Bramhall., et al.
Received: January 04, 2020

speed of application and cost. There is little doubt that the application of a clip is quicker and simpler than the application of an intra-corporeal knot and the use of stapling devices and the preformatted loop device are limited by cost. Most surgeons remain uncomfortable in using an energy device to seal the cystic duct.

The metal clip most frequently used to close the cystic duct is a non-locking device that closes the lumen by exerting pressure to oppose the two bile duct walls and then maintaining its position because of its tensile strength. The lack of a locking mechanism however means that should the pressure in the biliary system rise the clip can be forced off the duct leading to a bile leak. The locking clips are usually a non-absorbable polymer because they do not require tensile strength to allow them to maintain their position, they tend to be bowed (to allow removal if necessary), they have integrated teeth on the internal surface to help them maintain position once applied and they have a locking mechanism which provides tactile feedback and a secure closure. Similar locking clips are available that are absorbable, these are not in widespread use because of cost but have some theoretical advantages over nonabsorbable polymer clips however a systematic review (limited by small numbers) demonstrated no clinical advantage [10]. While a bile leak is still possible using a locking clip, they are less likely to be forced off by an increase in luminal pressure.

In our own unit, routine cystic duct closure is carried out using non-locking metal clips but a locking clip is used in selected cases. In a series of 844 laparoscopic cholecystectomies carried out over approximately four years, the locking clip was used in 233 cases with the others routinely getting non-locking metal clips. These were all in what one would consider more difficult laparoscopic cholecystectomies with almost $70 \%$ having either a wide cystic duct alone or in combination with a difficult gall bladder dissection. The incidence of procedure related post-operative complications was $4.7 \%$ with seven patients requiring an ERCP (5 with retained stones), one patient needing radiological drainage (not for a bile leak) and the remaining patients being treated conservatively (self-limiting bile leak into surgically placed drain). There were no 
bile leaks despite the requirement for post-operative ERCP. This is a however a small selective series of patients and therefore no attempt has been made to compare these data with patients having the non-locking metal clips applied to their cystic ducts.

In a recent systematic review of cystic duct closure in which more than 47,000 laparoscopic cholecystectomies were included, $81.5 \%$ of cystic ducts were closed with non-locking metal clips, $7.6 \%$ with a ligature, $3.9 \%$ with a locking clip, $2.7 \%$ with an absorbable clip and $4.3 \%$ with some form of energy device. The overall cystic duct leak rate was very low at $0.4 \%$ in the pooled data. The review describes a small failure rate detected at the time of the procedure, of the energy devices $6.7 \%$, of locking clips $2.8 \%$ and of ligatures $1.4 \%$, all of which required a change of technique, but does not report the failure rate of non-locking metal clips. The review was unable to demonstrate an ideal closure type but the pooled data points did suggest a lower cystic duct leak rate with locking clips and ligatures when compared to non-locking clips and energy devices [11].

In our own series, we have divided our patients into complicated and uncomplicated cholecystectomy and have applied an arbitrary decision to use locking clips on the complicated group and the cheaper, quicker and more expedient non-locking clips in the uncomplicated group. This approach appears to have been successful in our own practice but the definition of 'complicated and uncomplicated' will inevitably vary between surgeons.

Despite the frequency with which laparoscopic cholecystectomy is performed and the significant health burden associated with complications of the procedure there is a paucity of randomised controlled data addressing the ideal type of cystic duct closure. A small percentage reduction in cystic duct associated bile leakage could lead to significant financial savings to the healthcare economy and improve the quality of life of patients undergoing the procedure. Until such data are available, it will remain surgeons' preference as to the type of cystic duct closure that is carried out.

\section{Bibliography}

1. Thorlby R., et al. "NHS performance and waiting times - Priorities for the next government".

2. Radunovic M., et al. "Complications of Laparoscopic Cholecystectomy: Our Experience from a Retrospective Analysis". Open Access Macedonian Journal of Medical Sciences 4.4 (2016): 641-646.

3. McMahon AJ., et al. "Bile duct injury and bile leakage in laparoscopic cholecystectomy". British Journal of Surgery 82 (1995): 307-13.

4. Massoumi H., et al. "Bile leak after laparoscopic cholecystectomy". Journal of Clinical Gastroenterology 41 (2007): 301-305.
5. Strasberg SM., et al. "An analysis of the problem of biliary injury during laparoscopic cholecystectomy". Journal of the American College of Surgeons 180 (1995): 101-125.

6. Kandil T., et al. "Comparative study between clipless laparoscopic cholecystectomy by harmonic scalpel versus conventional method: a prospective randomized study". Journal of Gastrointestinal Surgery 14 (2010): 323-328.

7. Bessa SS., et al. "Clipless laparoscopic cholecystectomy by ultrasonic dissection". Journal of Laparoendoscopic and Advanced Surgical Techniques A 18 (2008): 593-598.

8. Matsui Y., et al. "Absence of cystic duct leakage using locking clips in 1017 cases of laparoscopic cholecystectomy". American Surgery 78 (2012): 1228-1231.

9. Yang CP., et al. "Efficacy of electrocoagulation in sealing the cystic artery and cystic duct occluded with only one absorbable clip during laparoscopic cholecystectomy". Journal of Laparoendoscopic and Advanced Surgical Techniques A 24 (2014): 72-76.

10. Gurusamy KS., et al. "Methods of cystic duct occlusion during laparoscopic cholecystectomy". Cochrane Database System Review (2010): CD006807.

11. van Dijk AH., et al. "Systematic review of cystic duct closure techniques in relation to prevention of bile duct leakage after laparoscopic cholecystectomy". World Journal of Gastrointestinal Surgery 10 (2018): 57-69.

\section{Assets from publication with us}

- Prompt Acknowledgement after receiving the article

- Thorough Double blinded peer review

- Rapid Publication

- Issue of Publication Certificate

- High visibility of your Published work

Website: www.actascientific.com

Submit Article: www.actascientific.com/submission.php Email us: editor@actascientific.com

Contact us: +919182824667 